\title{
MIASMAS, MICROBIOS Y CONVENTILLOS
}

\author{
Sandra Caponi \\ Depto. de Salud Pública \\ Universidad Federal de Santa Catarina, Argentina
}

\section{RESUMEN}

En este trabajo discuto las dificultades de universalizar la oposición propuesta por Ackerknecht entre infeccionismo y contagionismo examinando los efectos del pasteurismo en los discursos y las prácticas sanitarias. Muestro las rupturas y las continuidades entre la higiene clásica y aquella reorganizada a partir de la microbiología. En ese contexto analizo, como ejemplos puntuales, ciertas estrategias sanitarias de control de la vivienda popular propuestas por los higienistas de Brasil y Argentina.

PALABRAS CLAVE: higiene, salud pública, Argentina, Brasil, siglo XIX, siglo XX.

\section{SUMMARY}

In this paper I discuss the difficulties of generalize Ackerknecht's opposition between infectionism and contagionism by analyzing the influence of early pasteurism in the discourses and sanitary practices. I show the ruptures and the continuities between classical hygiene and that which has been reorganized by microbiology. In this context, I analyze, like particular examples, some sanitary strategies to control lower classes housing proposed by the hygienists of Argentina and Brazil public hygiene.

KEY WORDS: hygiene, public health, Argentina, Brazil, $19^{\text {th }}$ century, $20^{\text {th }}$ century.

La historia de la higiene nos obliga a detenernos en la lectura de autores oscuros y olvidados, de textos, documentos y archivos que hoy parecen carecer tanto de relevancia científica como de valor político. Anales y escritos que nos hablan de programas fracasados, de teorías refutadas y de debates anacrónicos. Sabemos, sin embargo, que entre esos papeles polvorientos persisten los restos de luchas, alianzas y conquistas científicas o políticas que pueden ayudarnos a comprender mejor nuestro presente. Pretendemos hacer de esos documentos un uso epistemológico y político, de manera tal que ellos nos permitan mostrar que entre las antiguas estrategias propuestas por los higienistas y aquellas que posteriormente serán sostenidas a la luz de los descubrimientos de la microbiología no existe necesariamente confrontación $u$ oposición, sino más bien una especie de solidaridad y complementariedad que puede 
ser verificada tanto en el horizonte de la historia conceptual cuanto en el horizonte de la historia social y política.

Resulta inevitable, por tanto, que revisemos ese argumento que insiste en afirmar que es necesario recuperar una vieja medicina pre-pasteuriana, preocupada con los problemas sociales más que con los microbios, una medicina referida a la pobreza y a los conflictos que de ella derivan, que desaparecería en ese momento preciso que surge una nueva figura: la del médico que deja de luchar contra la miseria para luchar contra pequeños seres, a simple vista invisibles, considerados como los verdaderos y únicos causantes de las enfermedades. Creemos que este relato lineal precisa ser cuestionado.

En primer lugar es preciso interrogarse por el estatuto teórico y político de la higiene pre-pasteuriana. ¿Cómo se constituyó ese espacio discursivo? ¿Qué estrategias concretas puso en práctica? ¿Cuáles eran sus preocupaciones y objetivos?. Es probable que entonces podamos observar que para muchos higienistas pre-pasteurianos la lucha contra la miseria podía significar, al mismo tiempo, dos cosas: un reconocimiento explícito y estadísticamente fundamentado de la necesidad de modificar las desigualdades sociales, pero también, la necesidad de multiplicar estrategias de control sobre el modo de vida de las clases populares.

A partir de Ackerknecht se afirma que el higienismo anterior a la así llamada «Revolución Pasteuriana» no constituía un bloque homogéneo sino que existieron dos corrientes confrontadas teórica y políticamente que podían ser reconocidas como infeccionistas y contagionistas. Pasteur había posibilitado la victoria definitiva de los segundos a partir del momento preciso en que logró desarticular la antigua creencia en la generación espontánea. Estas afirmaciones suponen ciertas certezas que precisan ser problematizadas. En primer lugar parece inevitable que nos interroguemos por la validez universal de la distinción de Ackernecht ${ }^{1}$. ¿Es posible reconocer esa misma oposición, en diferentes países y en diferentes circunstancias, o deberemos afirmar que las nociones de infección y contagio, pueden resultar tanto aliadas como antagónicas según sean los contextos políticos y sociales, o los intereses a ser defendidos?2. Por fin, será necesario analizar hasta qué punto es posible hablar de una contradicción absoluta entre los higienistas clásicos (que se supone, en su gran mayoría, eran anti-contagionistas) y las estrategias de los nuevos higienistas que se proponían luchar contra ese universo amenazador de lo «infinitamente pequeño».

1 La tesis de Ackerknecht formulada por primera vez en el texto clásico «Anticontagionism between 1821 and $1867 »$ de 1948 fue sometida desde entonces a críticas y defensas diversas. Nuestro interés es analizar su aplicabilidad y pertinencia para analizar la oposición infección-contagio y la emergencia del pasteurianismo en América Latina, más presisamente en relación a la medicina e Higiene Argentina y Brasileña de inicios de siglo. Ver ACKERKNECHT, E (1948) «Anticontagionism between 1821 and 1867». Bulletin of the History of Medicine, n. 22.

2 Ver: BouRdELAIS, P. (1988), Peurs et Terreurs face à la Contagion.. Fayard. Paris, p. 37; y BALDWIN, P. (1999) Contagium and the State in Europe. 1830-1930. Cambridge University Press. Cambridge, p. 17 
Nos limitaremos a mostrar de qué modo estas posiciones se articularon, se profundizaron o se anularon, en el caso específico de la construcción de algunas estrategias sanitarias puntuales. Así, examinaremos algunos de los argumentos que, entre fin del siglo XIX e inicios del siglo XX, fueron considerados, en Brasil y Argentina, en el contexto de algunas discusiones sobre la cuestión de la vivienda popular y las llamadas «islas de insalubridad».

Como intentaremos mostrar, si el discurso de la microbiología pudo integrarse al espacio del higienismo, a punto de modificar casi enteramente sus prácticas y su discurso, fue porque las estrategias de los higienistas ya se habían demostrado eficaces para el control de diferentes enfermedades; independientemente de la posición que ellos hubieran adoptado frente a los problemas derivados de las desigualdades sociales. La asociación entre clases pobres y clases peligrosas, forma parte del discurso de higienistas como Villermé o Virchow, aun cuando sus estudios permitieron establecer claras correlaciones entre mortalidad prematura y condiciones sociales de vida ${ }^{3}$.

Los controles sanitarios referidos a la vivienda popular, llamada de «conventillo», «tugurio» o «cortiço», así como la emergencia de su correlato (el visitador), ponen en evidencia que es posible hablar de complementariedad entre las diferentes estrategias sanitarias adoptadas por los higienistas clásicos y por el «nuevo higienismo» ${ }^{4}$ heredero de la llamada «Revolución Pasteuriana». Desde los estudios de Villermé sobre las condiciones de vida de los operarios de la industria algodonera hasta la reforma de Haussmann, que transformó la urbanización de París, un mismo tema se reitera: la necesidad de excluir, hacia las zonas rurales (Villermé) o hacia la «banlieue» (Haussmann), a las clases populares, identificadas con la peligrosidad moral en el primer caso, con la peligrosidad política en el segundo, y com la peligrosidad médica en ambos. Pero, es preciso no desconsiderar que la descripción hecha por Villermé de las habitaciones de los operarios puso al desnudo la inequidad; permitió establecer claras correlaciones entre ellas y la alta mortalidad de los trabajadores; evidenció la necesidad de legislar sobre el trabajo infantil, sin dejar de reiterar las preocupaciones «aeristas» clásicas. «Se encuentran en 1828 hasta 3687 alojamientos en cuartos subterráneos, estrechos, bajos, privados del aire del día, donde reina la suciedad, y donde reposan en una misma cama los padres, los hijos y los hermanos y hermanas adultas» ${ }^{5}$ «El día llega para ellos una hora más tarde que para los otros y la noche una hora más temprano» ${ }^{6}$.

\footnotetext{
3 Anne La Berge refiriéndose a estos higienistas hablará de una teoría social de la epidemiología. Ver: LA Berge (1992), Mission and Method, Cambridge University Press, Cambridge, p. 96

4 Ver: FAURE, (1993), Les Français et leur médecine au XIX siècle, Belin, París, p. 241 y ss.

5 VILLERMÉ, L. (1840), Tableau de l'etat physique et moral des ouvriers, 2 vols. París.

6 La relación entre condiciones físicas y morales que, como veremos, es una cuestión recurrente en el texto de Villermé, lo lleva a insistir en la relación entre esos cuartos estrechos y la existencia de relaciones incestuosas como algo común entre las clases pobres.
} 
Comprender el papel desempeñado por higienistas como Villermé, así como los cambios que la nueva higiene francesa debió sufrir a partir de los trabajos de Pasteur, parece indispensable para poder tornar inteligibles las intervenciones que fueron programadas por los higienistas argentinos y brasileños con relación a la vivienda popular hacia fines del siglo XIX e inicios del siglo XX. Tal como lo afirma Nancy Stepan existieron entonces fuertes vínculos entre los intelectuales de Latino América y los higienistas franceses, que, muchas veces implicaron una verdadera dependencia de la medicina Latino Americana de los discursos y estrategias adoptadas por los higienistas franceses?

\section{LA PASTEURIZACIÓN DE LA HIGIENE}

Para poder hablar de cierta continuidad entre las estrategias propuestas por los higienistas, en su gran mayoría defensores de explicaciones miasmáticas y de profilaxis de saneamiento y desinfección, y aquellas estrategias que se adoptaron con posterioridad a la llamada Revolución Pasteuriana es necesario revisar la tesis que afirma que ese momento representa el triunfo del contagionismo por sobre el infeccionismo. El análisis de las controversias científicas ocurridas en diferentes países pone en evidencia que no se trata de dos formas puras sino de dos modos de comprender la cuestión de la etiología de las enfermedades que por un largo tiempo pudieron convivir, aunque no sin dificultades.

Estos dos modelos de explicación fueron detenidamente analizados en el clásico texto de William Coleman «Death is a social desease». Aun cuando el mismo se centra en el estudio de Villermé y el higienismo francés pre-pasteuriano, nos permite caracterizar estos dos modos de comprender las enfermedades epidémicas que, en ciertas circunstancias precisas, se opusieron tanto teórica como políticamente. Para él, el estudio de Ackerknecht de 1943 fue el primero en identificar la intima conexión existente entre salud pública e intereses político-económicos, a partir del momento que señala los vínculos entre políticas conservadoras defensoras de las cuarentenas y teorías contagionistas. Para Coleman ${ }^{8}$ la disputa entre contagionistas e infeccionistas era un elemento especial de una cuestión más amplia cuyo tema principal eran las relaciones entre la civilización moderna y las condiciones médicas de la población. Por esa razón los reformadores generalmente se opusieron a la idea de «contagio vivo» como causa de las enfermedades y defendieron la tesis que afirma que la insa-

\footnotetext{
7 En «The hour of eugenics» Nancy Stepan da continuidad a su magistral estudio sobre la investigación científica en el instituto Oswaldo Cruz de Rio de Janeiro. Direcciona aquí su interés al nacimiento del eugenismo en América Latina y sus vínculos com la cienca europea.

8 Coleman, William (1982), Death Is a Social Disease. Public Health and Political Economy in Early Industrial France, Madison, The University of Wisconsin Press, p. 292.
} 
lubridad y las condiciones precarias de vida eran los verdaderos responsables por las epidemias. Edwin Chadwick, ferviente anticontagionista, centró toda su atención en la suciedad considerada único principio explicativo ${ }^{9}$. Villermé, por su parte, centró sus estudios en las condiciones precarias de vida de los obreros y prisioneros.

A pesar de la atención dedicada a este debate durante las últimas décadas, diversos estudios recientes, como por ejemplo el trabajo que Peter Baldwin dedica a la historia y epistemología de diferentes enfermedades tales como el cólera, la sífilis y la viruela, parecen mostrar la pertinencia de volver una vez más sobre esa distinción tantas veces repetida entre infeccionistas y contagionistas. A partir del análisis de documentos y archivos relativos a la historia de esas enfermedades, en diferentes países europeos, durante el período de 1830 a 1930, este autor concluye que entre esos diferentes modos de explicar las epidemias no existieron correlaciones lineales y unívocas sino cruzamientos y figuras intermediarias que no se agotaban en el esquema tantas veces repetido de miasmáticos-progresistas y contagionistas conservadores. Entiende que «una visión estrictamente binaria de la etiología (localismo vs. contagionismo) o de la profilaxis (estrategias sanitarias vs. cuarentena) puede resultar una distorsión. Los tres bloques básicos de la teoría epidemiológica ( factores locales, sea naturales o sociales, predisposición individual y contagio) eran múltiples y mutuamente permeables» ${ }^{10}$

Es posible que el análisis de la existencia de una enorme zona intermediaria entre contagionistas estrictos y infeccionistas estrictos (donde sí sería posible reconocer la oposición de Ackerknecht) nos permita hablar de un espacio donde convivieron diferentes modos de comprender la etiología de las enfermedades y de edificar esquemas profilácticas, que no se limitaban a repetir la oposición clásica. Es posible que, entonces, podamos entender de otro modo la relación entre el higienismo y la emergencia de la microbiología.

El reconocimiento de ese espacio donde convivieron estrategias que deberían ser opuestas puede permitirnos explorar la idea clásica que insiste en establecer una ruptura radical entre las estrategias de purificación y de saneamiento propias del higienismo pre-pasteuriano y la emergencia de la microbiología. Tal como lo afirma Bruno Latour ${ }^{11}$, esta última no decretó la muerte de la primera. Aun cuando pueda ser reconocida la existencia de un nuevo modelo explicativo (los complejos patogéni$\cos )^{12}$, podemos observar la permanencia de estrategias «purificacionistas» de carácter universal que persistieron, en muchos casos por su operatividad, en diferentes

\footnotetext{
9 Coleman (1982), p. 156.

10 Baldwin, P. (1999), Contagium and the State in Europe. 1830-1930, Cambridge, Cambridge University Press, p. 8

11 LAtouR, B. (1988), The Pasteurization of France, Harvard University Press. Cambridge.

12 La distinción entre el espacio de la purificación y el espacio de los complejos patogénicos es analizada por François Delaporte en Les Epidemies.
} 
países y a propósito de diferentes enfermedades (tal es el caso, por ejemplo, de la profilaxis de la fiebre amarilla en Argentina a inicios del siglo XX).

Existió una fase ecléctica donde convivieron la preocupación por los microbios, y la obsesión por la purificación. Así, resulta significativo que, durante algún tiempo, las medidas profilácticas se dirigieran, prioritaria y exclusivamente, a las letrinas y cloacas a las cuales, según se creía, se limitaban los microbios: «para el microbiologista Paul-Louis Keiner los «reservorios» microbianos se limitaban a las letrinas y a los desagües en primer lugar y al suelo en segundo lugar» ${ }^{13}$. Estos espacios de encuentro entre dos discursos aparentemente irreconciliables nos permiten cuestionar la tesis que nos habla de paradigmas kuhnianamente inconmensurables ${ }^{14}$. La existencia de espacios de convivencia entre miasmas y microbios, entre enfermedades que eran pensadas como efecto de la «suciedad» y enfermedades que encontraban su explicación en los bacilos y bacterias, así como la convivencia entre profilaxis centradas en la purificación y aquellas centradas en la desinfección, nos permite cuestionar la tesis que habla de una ruptura radical entre posiciones antagónicas.

Si nos detenemos allí donde esas estrategias se encuentran y se solidarizan veremos algunos puntos de contacto significativos que se reiteraron en el momento de definir medidas profilácticas para las diferentes epidemias. Estrategias tales como la desinfección de los espacios, el control de la vivienda popular y el control de los inmigrantes se repitieron antes y después de la revolución pasteuriana. A partir de allí, los higienistas, sean infeccionistas o contagionistas, intentaron controlar y detener las epidemias que se reiteraban tanto en América Latina como en el resto del mundo: cólera, fiebre amarilla, tuberculosis, sífilis. Hoy aquellas viejas enfermedades de la pobreza, que creíamos erradicadas y superadas, reaparecen con fuerza extrema e inesperada, al mismo tiempo que nuevas enfermedades epidémicas e infectocontagiosas amenazan a las poblaciones. Conocemos la directa vinculación existente entre la distribución de ciertas enfermedades y el modo como se distribuye la pobreza, sea en el interior de cada país, sea a escala mundial. Sin embargo, las diferencias persisten así como persisten los viejos flagelos que podrían ser evitados.

Quizás, sea allí donde la historia de la ciencia puede resultar un auxilio eficaz para comprender el proceso de construcción de las teorías y de las estrategias de prevención actualmente existentes. Una vez mas los países de Latinoamérica (nos referimos principalmente a Brasil y Argentina) se enfrentan con la necesidad de controlar esas viejas enfermedades epidémicas y endémicas que insisten en retornar (malaria, cólera y lepra por un lado, tuberculosis y sífilis por otro). Una vez más, el saneamiento de las viviendas populares y el control de las fronteras resultan ser los dos espacios privilegiados de acción de los gobiernos y de sus estructuras sanitarias. Reiterada-

13 Murard, L. y Zylberman, P. (1996), L'Hygiène dans la République, Fayard, París, p. 101.

14 SAlomon-BAYet, C. (org) (1986), Pasteur et la Revolution Pastorienne, Payot, París, p. 25 y ss. 
mente ese saneamiento se asociará al control de la vivienda popular y en consecuencia al control del modo de vida de las clases populares. Se reproduce así una vieja estrategia que surgió con el higienismo, desde las estadísticas de Villermé sobre las condiciones de vida de los obreros del algodón, la «ebriedad» y la «promiscuidad» nunca dejaron de ser objeto de preocupación para los higienistas. Por otra parte, aún hoy, el control de las fronteras parece no poder escapar de consideraciones referidas a una supuesta peligrosidad de los inmigrantes, como lo atestiguan los conflictos existentes en Argentina con la inmigración de países limítrofes (prioritariamente los inmigrantes de Bolivia).

Así por más de un siglo continuamos reiterando una misma creencia que parece haberse convertido en certeza por la fuerza de la repetición, para poder controlar las epidemias parece necesario auxiliar-controlar aquellos sujetos que se mantienen al margen de la sociedad: pobres, desempleados e inmigrantes. Es en el interior de esa polaridad entre auxilio y punición, entre solidaridad y vigilancia, que se multiplican los conflictos, las dudas y las certezas que parecen haber marcado la historia del higienismo, una historia que comprende tanto al higienismo clásico preocupado con los miasmas o con el «contagium vivo» como a los «nuevos» higienistas preocupados con bacilos, parásitos y bacterias.

¿De qué modo y bajo qué condiciones fue posible, en ese momento inaugural de la historia de la medicina argentina y brasileña, la convivencia de esas formas discursivas: microbiología e higiene clásica? ¿De qué modo el saber médico, que parecía finalmente haber alcanzado su estatuto de cientificidad, pudo convivir con las estrategias purificadoras de los higienistas? Se puede afirmar que: «Antes de Pasteur, la relación entre enfermedad y miseria era directa. Con la revolución microbiana, comenzó a ser aceptado que el espacio social de las epidemias, ya no estaba exclusivamente ocupado por pobres, sucios, vagabundos o locos, pues aun el hombre sano era portador de gérmenes» ${ }^{15}$. Entonces, resulta necesario analizar de qué modo las estrategias de gestión, de control y de moralización referidas al mundo de la pobreza permanecieron y se integraron en un nuevo esquema sanitario que privilegiaba (a partir de Pasteur y Koch) el combate a los microbios sin por ello dejar de referirse a las condiciones de vida. Intentaremos mostrar de qué modo, y a partir de qué prácticas concretas, pudieron convivir, sin grandes conflictos, el discurso científico referido a los microbios con las estrategias higienistas clásicas de limpieza, saneamiento y moralización. Con la finalidad de analizar si es o no posible hablar de continuidad, resulta indispensable caracterizar al higienismo clásico, tanto en lo que se refiere a las estrategias que hoy podemos considerar operativas y necesarias, como en relación con aquellas que hoy pueden ser consideradas superfluas, no equitativas o injustas.

\footnotetext{
15 ARMus, D. (org.) (1995), Huelgas, Habitat y Salud, Sudamericana Buenos Aires, p. 88.
} 


\section{LA EMERGENCIA DEL HIGIENISMO}

Como respuesta a los temores y angustias provocados por la aparición de diversas epidemias, se generalizó una preocupación por el espacio urbano tendiente a garantizar la circulación del aire purificado: liberado de miasmas. Así, en el año 1776 fue realizada en Francia la primera investigación sanitaria encargada por la Academia de Medicina para intentar descubrir el origen de las epidemias: «centenas de médicos han censado a los enfermos, a sus ciudades y villas, han relevado las horas de las mareas, la fuerza de los vientos, la cantidad de lluvias. Sus informaciones se extendieron al estado de las calles, de las habitaciones y cuartos de los trabajadores. El conjunto de esos datos crea un género, el de la topografía médica, síntesis inicial de los primeros balances sanitarios efectuados sobre una comunidad» ${ }^{16}$.

Esta topografía médica que fue el punto de partida para diversas intervenciones urbanas sanitarias, anticipaba un hecho que, años más tarde se convirtió en ineludible; la exigencia de cuantificar y calcular, con cifras lo mas precisas posibles, el estado sanitario de una ciudad.

Vinculada a la extensión de esa «topografía» ocurrió un segundo hecho significativo: en el año 1786 el cementerio des Saints-Innocents de Paris fue cerrado, exhumado y desplazado. La noche del 7 de abril de ese año fueron trasladados los cuerpos cubiertos con banderas negras, de modo tal que «la teoría del aire mefítico había impuesto por primera vez el alejamiento de los muertos del interior de las ciudades» ${ }^{17}$.

El tercer hecho significativo fue la emergencia del hospital medicalizado y de la clínica. En el año 1780 fueron realizadas las investigaciones necesarias para poder evidenciar los limites y las dificultades de los hospitales de caridad hasta entonces existentes. A partir de allí, el hospital dejaba de ser ese espacio donde las personas pobres esperaban la muerte, para pasar a ser un espacio de observación, un espacio médico de enseñanza donde debía existir un registro exhaustivo de los enfermos y de sus enfermedades. El nuevo hospital donde la figura del médico sustituía a la religiosa debería ser un espacio creado para permitir la circulación del aire, preocupación central para los médicos de fin del siglo XVIII.

El estado higienista del siglo XIX puede situarse en el entrecruzamiento de estos tres hechos significativos: (a) el nacimiento del hospital medicalizado, (b) la preocupación por la cuantificación y el uso de las estadísticas y (c)la renovación del aire como exigencia médica.

La medicalización del hospital parece situarse a mitad de camino entre el «aerismo» y las estadísticas. La emergencia del hospital no escapaba al temor del aire mefítico y en consecuencia su localización en la ciudad debía responder a las exigencias de la topografía médica; tampoco escapaba de las exigencias de cuantificación pues, en la

16 Vigarello, G. (1999), Histoire des practiques de santé, Seuil, París, p. 183.

17 Ibidem, p. 185. 
medida en que debía garantizar la existencia de un registro permanente de todo lo que ocurría en su interior, se convertía en una fuente inestimable de conocimientos y de datos que podían ser contados, distribuidos, calculados y comparados.

La higiene encontraba las condiciones de posibilidad de su emergencia entre los miasmas y los números. La purificación del aire y las estadísticas eran los instrumentos privilegiados tanto para consolidar su discurso como para garantizar la eficacia de las intervenciones propuestas. Esos instrumentos permitían actuar simultáneamente en la reorganización urbana, preocupada con los olores y con su percepción, y en el interior del hospital, espacio privilegiado de observación de la enfermedad.

La antigua nosología era desplazada y dejaba lugar a la nueva asociación entre la anatomía patológica y la clínica. Con Broussais, y a pesar de sus inútiles sangrías y sanguijuelas, la medicina devino finalmente «fisiológica», a cada síntoma se le podía atribuir una causa precisa, y esa causa debía ser procurada en la irritación (inflamación) de los tejidos del «órgano sufriente». A partir de allí se transformó en obligación médica: «(a) Determinar cuál es el órgano que sufre; (b) explicar cómo el órgano ha devenido sufriente, considerando que la irritación puede provocar hiperactividad o astenia funcional; (c) indicar qué se debe hacer para que cese de sufrir, esto es, suprimir la causa (el frío en la pulmonía) $)^{18}$.

Por inflamación se entendía una irritación provocada en todos los tejidos por el contacto con un cuerpo extraño, agentes vivos o no vivos, exteriores o interiores pero que, de todos modos, eran extraños al funcionamiento de ese órgano: sea que se tratara de una alteración de clima, de una variación en el régimen alimentario o de cualquier otra alteración.Como afirmó Broussais: «Después de muchas vacilaciones en su marcha, la medicina sigue, en fin, la única ruta que puede conducirla a la verdad: la observación de las relaciones del hombre con las modificaciones externas, y de los órganos de los hombres unos con los otros» ${ }^{19}$.

A partir de entonces podía decirse que a cada síntoma le correspondía una alteración orgánica observable. El espacio de la enfermedad había devenido un espacio causal, y esa causalidad era ahora observable a través de la alteración de los tejidos que indicaban la existencia de agentes extraños que provocaron esa inflamación. El médico podía, entonces, establecer una alianza entre los dos roles que le eran atribuidos: «el conocimiento, a través de la anatomo-clínica y la prevención a través de la higiene». Es verdad que la escuela anatomo-clínica se encontraba dividida entre los partidarios de la teoría de Broussais y otros que, como Laënnec, creían en la existencia de entidades mórbidas específicas, cuyas causas misteriosas podían, sin embargo, ser transmitidas ${ }^{20}$.

18 Foucault, M. (1997), Naissance de la clinique, PUF, París, p. 195.

19 Ibidem, p. 193.

20 Para J. Leonnard, que considera válida la distinción de Ackerknecht antes analizada, esta misma diferencia se reproduce en el ámbito de la policía sanitaria «entre los infeccionistas, generalmente brous- 
$\mathrm{Si}$, por una parte, la emergencia del hospital medicalizado debe considerarse como condición de posibilidad de ese nuevo espacio causal al que se vinculaban las afecciones orgánicas observables, por otra parte, es también ese espacio el que posibilitó que el sueño de cuantificar la enfermedad se creyera finalmente alcanzado. Pierre Louis (1820-50) pretendía crear, lo que dio en llamar «medicina numérica». La misma partía de la convicción de que era «posible estudiar en el hospital una población de enfermos de la cual se registraban todos los síntomas. Después de la muerte se estudiaban todas las lesiones anatómicas y finalmente se intentaba hacer una relación entre las lesiones y los síntomas registrados. Se creía que multiplicando estas observaciones se podrían construir series estadísticas que auxiliarían a descubrir las causas de las enfermedades $»^{21}$.

Entonces, las enfermedades se convirtieron en objeto de estudios estadísticos a través de dos caminos diferentes. Dentro del hospital para evaluar las terapéuticas y tentar establecer correlaciones etiológicas, como lo hacía Louis a partir de los registros de enfermos del hospital. Fuera del hospital, los higienistas de la primera mitad del siglo $\mathrm{XIX}^{22}$ utilizaron estudios estadísticos que partían de la comparación y análisis de las tablas de mortalidad con la finalidad de descubrir leyes capaces de explicar las regularidades observadas ${ }^{23}$. William Farr en Inglaterra y Louis Villermé en Francia construyeron estudios epidemiológicos sobre las condiciones de vida de los operarios que dieron el fundamento para imprescindibles reformas legislativas (ley de 1841 limitando el trabajo de niños) a pesar de carecer aún de modelos matemáticos muy elaborados.

La historia de la higiene parece ser inseparable de un proceso de matematización de la enfermedad. Ya en el siglo XVIII los higienistas habían iniciado este proceso de cuantificación, con las investigaciones aerísticas (como la que fue lanzada en 1776 por la Academia de Medicina) que encontraron un fundamento teórico consistente una vez que Lavoisier ${ }^{24}$ realizó sus experiencias con el oxígeno y la respiración. El aire se convertía entonces en el tema privilegiado de los higienistas, y el laboratorio ingresaba al ámbito de los estudios médicos. Ya no se trataba de una preocupación por el perfume sino por ese elemento esencial que permite respirar y vivir. Toda la distribución del aire debía ser re-pensada, era necesario remodelar los espacios, descubrir los lugares donde se concentra el aire viciado, actuar sobre el medio. Para ello era necesario conocer la realidad del mismo, calcular la cantidad de agua y de

saisistas que preconizan una política de prosperidad y de higiene pública y los contagionistas que defienden la existencia de lazaretos y cuarentenas». Ver: LEONNARD, J. (1992), Médicins,Malades et Societé. Sciences en Situation, París, p. 223.

21 JORLAND, G. (1999/2000), Séminaire «Les Lumières Scientifiques: Le mouvement hygiéniste en France au XIXéme siécle», París, École des hautes etudes en sciences sociales.

22 OCAÑA, E. R. (1992), Por la salud de las naciones. Higiene, Microbiología y Medicina social, Madrid, AKAL, núm. 45, p.12 y ss.

23 GrmeK, M. (1999), Histoire de la pensée médicale en occident, Seuil, París, p. 277.

24 Lavoisier, E. (1777), Memorias. L'air et L'eau, París, Librairie Armand Colin, ed. de 1923. 
aire necesarios para los seres vivos según las diferentes circunstancias. Lavoisier traducirá en cifras la cantidad de oxígeno que era necesaria para la realización de diferentes acciones según sea la edad, el sexo, la salud o la fuerza de quien lo consumía $^{25}$. Esas cuantificaciones se multiplicaron con relación a los tísicos, indicando la necesidad de renovar el aire y de transformar los espacios de vida. Estos estudios conducían a la instauración de un nuevo dispositivo higienista de prevención que parecía confirmar las utopías imaginadas por la topografía médica.

Diferentes autores ${ }^{26}$ han observado que el higienismo de inicios de siglo aparecía bajo la forma de un neo-hipocratismo o de un hipocratismo transformado a la luz de los descubrimientos de la química. Esta corriente se caracterizaba por su creencia en el «aerismo». «Se designa por ese término la convicción de que las afecciones y la contaminación se producían por el aire más que por el agua. La química aureolada por los recientes descubrimientos de Lavoisier sobre el análisis del fenómeno respiratorio y la identificación del gas carbónico venía a reforzar esa corriente» ${ }^{27}$. La preocupación con el agua era inevitable a partir del momento que se suponía que de allí emergerían gases tóxicos que contaminarían el aire. La cuestión de los pantanos se inscribe enteramente en ese espacio de discusión.

Desde 1777, cuando Lavoisier presenta en París su trabajo sobre la respiración, el aire y los estados del mismo pasan a ocupar el centro de las preocupaciones de los higienistas. Como afirma Lavoisier ${ }^{28}$ en sus Memorias sobre el aire y el agua: «De todos los fenómenos de la economía animal, no hay ninguno más digno de atención para médicos y fisiólogos, que aquellos que acompañan a la respiración. Sabemos que esa es una función esencial a la vida, que ella no puede ser suspendida sin exponer el animal al peligro de una muerte próxima. El aire, como todo el mundo sabe, es el agente, el sujeto de la respiración, pero, al mismo tiempo (...) hay un gran número de aires que los animales no pueden respirar». Era necesario diferenciar entre los diferentes «fluidos elásticos» aquellos propios y aquellos impropios para la respiración. Entonces, se decía que: «la respiración actuaba únicamente sobre la parte de aire puro o desflogistizado (oxígeno) contenido en la atmósfera; el residuo aéreo o parte «mefítica» no es más que una materia pasiva que entra y sale de los pulmones sin cambios sensibles $»^{29}$. Lavoisier comprobó experimentalmente que, un animal enfermo en un espacio que contenga aire mefítico y limitado oxígeno, muere. En ese

\footnotetext{
25 Cfr. Vigarello, G. (1993), «Modeles anciens et modernes d'entretien de la santé», en Comunications, $\mathrm{n}^{\circ}$ 56, Seuil, París.

26 Ver: VigARELlO (1999), BOURDELAIS (1988), ACKERKNECHT, E (1986), La médecine hospitaliére à Paris, Payot, París.

27 LÉCuYer, B. (1986), «L'Hygiène en France avant Pasteur», en Salomon-Bayet, C.(org) Pasteur et la Revolution Pastorienne, Payot, París, p. 71

28 LAVOISIER (1777), p. 55.

29 MAzzolini, R. (1997), «Les lumières de la raison: des systèmes médicaux à l'organologie naturaliste», en Grmek, M. (1997), Histoire de la pensée médicale en occident, Seuil, París, p. 112.
} 
proceso el calor jugaba un papel determinante, pues la respiración se definía como un tipo de combustión. Nociones y conceptos tales como, calórico, aire mefítico, oxígeno, gases tóxicos, formaban la trama discursiva en la que se sustentaban las intervenciones del higienismo.

«Jean-Noel Hallé, titular de la cátedra de física médica y de higiene en la Ecole de Santé no dudaba en situar la cuarta época de su Historia de la Higiene en el momento de (...) la revolución química que ha permitido el conocimiento de los «fluidos aeriformes» ${ }^{30}$. Así, en la Segunda mitad del XVIII las ciudades fueron objeto de «censos médicos» y fueron transformadas: los cementerios fueron desplazados a la periferia, se pretendió destruir las calles estrechas «acusadas de mantener los muros opuestos tan cerca que comprimía los pulmones $\rangle^{31}$, se trasladaron los mataderos y se cubrieron los pantanos. «Desde el fin del XVIII e inicios del XIX todos los elementos que podían alterar la calidad del aire fueron controlados, se trate de cementerios próximos de las ciudades, de actividades artesanales o de industrias que contaminan la atmósfera $»^{32}$. Este mismo proceso, que se repitió de modo casi idéntico en diferentes países, también ocurrió en Brasil y Argentina algunos años mas tarde.

\section{LA VIVIENDA POPULAR HIGIENIZADA}

Entre las estrategias edificadas por los higienistas clásicos y aquellas estimuladas por el nuevo higienismo pasteuriano es posible hablar de continuidad. No todas las estrategias fueron, como en el caso específico de la vacunación, diferentes a las estrategias anteriores. Es posible analizar la permanencia de ciertas estrategias clásicas referidas al medio que, aun cuando se refirieran a microorganismos, permanecieron prácticamente inalteradas. Era esto lo que ocurría cuando se hablaba de la necesidad de controlar la vivienda popular y de excluir los barrios y casas populares del centro a la periferia.

La cuestión de la vivienda popular «higienizada», que aparece de modo insistente durante la segunda mitad del XIX e inicios del XX, parece surgir del encuentro de, por lo menos, tres series discursivas: (a) la emergencia de la microbiología y su relación (no necesariamente de oposición) con el higienismo y con las explicaciones aeristas (b) la generalización de la estadística como recurso capaz de poner en evidencia la relación entre las desigualdades sociales y las diferencias en la mortalidad de la población; (c) la preocupación sanitaria y jurídica de controlar y moralizar las conductas de los sectores menos privilegiados de la población, o, dicho de otro modo, la persistencia de la antigua asociación entre condiciones físicas y condiciones morales.

\footnotetext{
30 REY, R. (1993), «Hygiène et souici de soi», en Comunications, nº. 56, Seuil, París, p. 33.

31 Vigarello, G. (1985), Le prope et le sale, Seuil, París, p. 185.

32 BOURDELAIS, P. (1988), p. 33.
} 
No es simple distinguir, en el tejido confuso de las argumentaciones estas dos últimas series discursivas. Las estadísticas diferenciales de mortalidad casi inevitablemente hacían aparecer, entre los ítems a ser evaluados, elementos de carácter moral tales como la promiscuidad, el abandono, la ebriedad, etc. Tanto Villermé como Parent Duchatelet en los textos fundadores del higienismo nos permiten observar la vinculación estrecha que existe entre la cuantificación y la preocupación con los considerados problemas «morales». En el primer caso las estadísticas se referían a la ebriedad y promiscuidad sexual, en el segundo caso a la prostitución. Las estadísticas, estaban dirigidas también a diferenciar los indicadores de mortalidad entre ricos y pobres.

Todo indicaba que una nueva amenaza emergía junto con el aire viciado, las calles estrechas, los lugares cerrados. Poco a poco esa medicina del medio pasó a ocuparse de una nueva figura: «los desheredados de las fábricas», las clases pobres, que pasaron a ser visualizados como médicamente peligrosos. Proteger a la sociedad contra esa amenaza exigía conocer sus condiciones de vida, y más importante aún, las condiciones de sus muertes. La estadística aparecía, tanto en Europa como en América Latina, como el mejor instrumento para conocer esa realidad. Así, para el higienista argentino Guillermo Rawson: «quienes hayan tenido oportunidad de observar la vida que se pasa en esas habitaciones malsanas que venimos estudiando, podrán comprender que de la alta cifra de defunciones, 2.200 al menos, procedían de las casas de inquilinato, lo que daría, sobre los 64.156 habitantes que ellas tenían, una mortalidad de 34 por mil. Entonces se puede apreciar la influencia perniciosísima que esas casas ejercen por la difusión de las enfermedades infecciosas, y la gravedad que ellas asumen en esos focos horribles desde donde se transmiten al resto de la población» ${ }^{33}$.

Ese momento puntual de la historia del higienismo no puede ser pensado exclusivamente en términos de violencia y dominación, las estrategias de poder represivas y poco equitativas que efectivamente existieron, convivieron con estrategias de saneamiento necesarias y efectivas. Las estrategias utilizadas posibilitaron una comprensión del estado sanitario de las diferentes clases sociales y evidenciaron la necesidad de modificar esas desigualdades. Las estadísticas de Villermé ponen al desnudo las diferencias de mortalidad existentes entre diferentes clases, diferentes profesiones y diferentes tipos de comportamiento ${ }^{34}$. Como afirma Anne La Berge ${ }^{35}$ : «médicos como Villermé estaban motivados por sentimientos humanistas. Ignorar esas motiva-

33 RAWson (1885), apud Páez (1970), El conventillo, Buenos Aires, Centro Editor de América Latina, p. 17.

34 Patrice Bourdelais (1988) señala que Villermé denuncia en realidad una correlación entre enfermedad y falta de salubridad más que entre enfermedad y pobreza. Es eso que lo lleva a afirmar que la mortalidad es más baja en el caso de las empleadas domésticas pues sus alojamientos son mas higiénicos, desconsiderando que existe una amplia escala en la pobreza que sitúa a estas mujeres muy por arriba de los trabajadores flotantes y desempleados.

35 La Bergue, A. (1992), p. 181. 
ciones humanitarias puede llevar a distorsionar la visión del movimiento de higiene pública». Claro que esto no implica afirmar que la historia del movimiento higienista haya sido ajena a estrategias de exclusión, moralización o control.

La higiene se apoyaba sobre una matematización de la sociología empírica. Colectar los hechos, seriar los casos, establecer correlaciones entre variables pertinentes, medir la incidencia de la edad, del sexo, de la profesión, del domicilio, de la alimentación era designar una semiología de la salud y del mal biológico ${ }^{36}$. Esos datos, números y estadísticas permitieron la realización de un cierto número de reformas tales como la legislación que limitaba el trabajo infantil o las leyes de saneamiento y reforma urbana. Desde su inicio la higiene surgió de un conflicto: por un lado, respondía a la necesidad de mostrar, de poner en evidencia las inequidades sociales; por otro, parecía no poder evitar transformar esos datos en indicadores de comportamientos que debían ser vigilados y modificados.

Así, en el año 1907 la correlación evidenciada por las estadísticas entre pobreza e incidencia de tuberculosis pudo llevar a los higienistas brasileños a defender la necesidad de edificar viviendas populares que cumplieran con los requisitos higiénicos de aireación y privacidad, pero, pudo llevar también a afirmar la necesidad de crear estrategias de vigilancia generalizada. "A vigilância exercida pelo dispensário estende-se desde o principio do corrente ano também aos enfermos pobres que se hospitalizam no nosocômio Santa Casa de Misericórdia, no Hospital Samaritano, na Maternidade (...) De maneira que se possa afirmar que a grande maioria dos alojamentos dos tuberculosos necessitados se acham sob nossas vistas, sob nossa guarda e superintendência higiênica» ${ }^{37}$.

En Argentina aun cuando existieron algunos intentos de utilizar los registros de mortalidad como en el caso de Rawson, solo fue con Emilio Coni a inicios del siglo XX que se instituyeron estudios estadísticos de valor explicativo. En el II Congreso Latino Americano de 1904 presentó un completo y útil estudio sobre las estadísticas demográficas sanitarias comparadas, de las cinco capitales Latino Americanas: Buenos Aires, Río de Janeiro, Santiago, Montevideo y Lima. Pero, Coni realizó también estudios estadísticos sobre alienación mental y su vinculación con el alcoholismo que lo llevaron a defender la «fundación de asilos de templanza», esto es, casas de secuestro o encierro de alcohólicos. Esta tesis duramente criticada por higienistas franceses fue defendida por Coni en estos términos: «La secuestración de un alcohólico no implica, a mi juicio, un ataque a la libertad individual. Todo el mundo sabe que un ebrio constituye un peligro para la moralidad y la seguridad. La estadística muestra que gran número de crímenes son cometidos por influencia del alcohol y en consecuencia las autoridades procederían con razón aislando esos elementos perniciosos» ${ }^{38}$.

\footnotetext{
36 LEONNARD, J. (1993), p. 225.

7 Anales del III Congreso Médico Latino Americano, (1907), Montevideo, p. 131.

38 CONI, E. (1918), Memorias de un médico higienista, Buenos Aires, Biblioteca Médica, p. 547.
} 
Todo un ejército de visitadores estaba encargado de controlar estos desvíos realizando una vigilancia minuciosa acompañada de consejos más o menos obvios y difícilmente aplicables. Con la finalidad de evitar que los recursos destinados a la caridad fueran desperdiciados, el visitador brasileño debía cumplir la misión de «ver por si mesmo as condições que levaram à agravação o que presidiram à explosão da moléstia e poderá sugerir modificações que operem uma melhora das condições. Alem disso, o visitador poderá descobrir a necessidade imperiosa de um exame cuidadoso para outro membro da família» ${ }^{39}$. La cuestión de los visitadores domiciliarios, repartidos por cuadras, era considerada como soporte indispensable para garantizar las políticas de redistribución urbana y de exclusión de los alojamientos insalubres. Ellos debían verificar de cerca las condiciones de salubridad de esos alojamientos, decir cuáles podían ser reformados y cuáles debían ser destruidos. Los Anales del Congreso Médico Latino Americano de 1907 evidencian la proximidad existente entre Brasil, Argentina y Francia, en lo que se refiere al papel desempeñado por los visitadores domiciliarios en el control de las epidemias.

La destrucción de barrios insalubres o «islas de insalubridad» ocurre en Latino América según el modelo de la reorganización urbana de París dirigida por el Barón Haussmann ${ }^{40}$ : «La destrucción de los barrios insalubres, en los cuales vivía la población más pobre, los obligaba a alejarse hacia otros barrios insalubres pero en la periferia o el suburbio». Recordemos que el proceso de «haussmanización» que transformó completa y radicalmente la urbanización de Paris, estaba articulado en torno a la creación de numerosos y ricos bulevares. «Los mismos bulevares que transforman la vida urbana creando espacios públicos, deliberadamente excluyen a los pobres fuera de la nueva ciudad, fuera de la mirada de los burgueses $\rangle^{41}$. Este proceso no implicaba ni supresión, ni desaparición, ni mejoramiento de las condiciones de los más pobres sino «desplazamiento». Si antes de Haussmann la pobreza y los barrios insalubres estaban localizados en el centro de la ciudad, después de Haussmann esos espacios fueron desplazados a pesar de existir algunas pocas excepciones ${ }^{42}$.

Vemos reproducir exactamente este mismo esquema en Río de Janeiro, a inicios de siglo, con la reforma urbana de Pereira Passos. Se realizaron entonces un conjunto de obras tendientes a sanear y «embellecer» la ciudad. Tal como ocurriera en París se construyeron en Río grandes avenidas y edificios suntuosos, pero «por primera vez

39 ACML (1907), p. 111.

40 Cfr. Benchimol, J. L. (1990), Pereira Passos: Um Haussmann tropical, Biblioteca Carioca, Río de Janeiro, p. 193 y ss.

41 BOURDELAIS (1988), p. 35. JORDAN, D. (1995), Transforming Paris: the life and labors of Baron Haussmann, The Free Press, New York, p. 354.

42 En «Transforming Paris» David Jordan hará un minucioso análisis de este proceso. Entre las excepciones significativas a este proceso señala la permanencia del «Quartier Latin» aunque muestra la existencia de cierta operatividad en esa permanencia. 
en su historia centenas de edificios fueron rápida e implacablemente demolidos, dejando a la intemperie a millares de personas -trabajadores y gente pobre» ${ }^{43}$. La preocupación con la vivienda no era nueva, existieron proyectos diversos tendientes a solucionar el problema «sanitario y moral» creado por aquello que se consideraban focos de insalubridad.

En 1870 después de la epidemia de fiebre amarilla, ya se había planteado la necesidad de excluir los barrios insalubres del centro de la ciudad. Se insistía en la necesidad de sacar a los habitantes de los «cortiços» y diseminarlos, separarlos, «alejarlos». Sin embargo, en ese momento pudo anticiparse una objeción que la reforma de Pereira Passos consideró, mas tarde, como irrelevante: destruir las viviendas precarias, «sería por cierto una preocupación de suma utilidad, pero ¿para dónde llevar a las 20.000 personas que en ellas habitan? ¿Quién las sustentaría, quién las cuidaría para que no huyeran para volver a los focos de infección? ¿Dónde encontrar las habitaciones para acomodar a toda esa gente? $\rangle^{44}$.

Evidentemente, pocos años después de instaurada la reforma urbana, esa misma preocupación, reaparecía. En el III Congreso Latino Americano, específicamente en la Cuarta Sección dedicada a la lucha contra la tuberculosis, los temas de la vivienda popular y de las islas de insalubridad fueron reiteradamente apuntados tanto por los representantes brasileños cuanto por los representantes argentinos. En 1907 Asevedo Lima, presidente de la liga contra la Tuberculosis ${ }^{45}$, afirmaba: «com a derrubada de milhares de prédios para saneamento da cidade, as classes proletárias tem sido forçadas a crearem habitações coletivas nas piores condições de habitabilidade» ${ }^{46}$.

Exactamente este mismo esquema se reiteró en Argentina. La ciudad de Buenos Aires que era pensada entonces como modelo de ciudad higiénica y saneada y que aparecía ante Río de Janeiro como «su gran rival, definitivamente expurgada de la mala fama de ciudad apestada ${ }^{47}$, no había conseguido aún liberarse del problema de los conventillos. Como en Brasil, el modelo que se utilizó para comenzar a pensar soluciones para este problema es el modelo de París. Emilio Coni, presidente del III Congreso Médico Latino Americano y delegado por Argentina, consideraba que el saneamiento sería completo cuando todos los habitantes pudieran gozar del aire y de la luz a la que tenían derecho. Dirá que «a la habitación salubre se liga íntimamente el registro o casillero sanitario de la habitación, que Francia ha sido la primera en implementar bajo el nombre de casier sanitario de la habitación $\rangle^{48}$.

\footnotetext{
43 BENCHIMOL, J. (1990), p. 316.

44 Pereira Rago Apud BenCHIMOL (1990), p. 138.

45 En 1905 es nombrado, por el ministerio del interior, miembro de una comisión para proponer soluciones al urgente problema de las habitaciones populares colectivas.

46 ACML (1907), p. 40

47 BenCHIMOL (1990), p. 138.

48 ACML (1907),p. 13.
} 
Los visitadores domiciliarios contribuyeron, con sus informaciones a llevar ese registro de la insalubridad. «Por la mediación de entrevistas se intentaban detectar los peligrosos portadores de gérmenes, en cuanto esto ocurría, un asistente social (o enfermera) reeducaba a la población con consejos morales e higiénicos. Ambos instrumentos demostraban que el espacio era visto como una unidad sanitaria donde el fantasma del contagio estaba presente casi cotidianamente ${ }^{49}$ Esto exigía la creación de una comisión de alojamientos insalubres capaz de evaluar donde debían ser operadas reformas o demoliciones. El foco de la atención estaba en la vivienda colectiva del centro de la ciudad y es por eso que uno de los objetivos centrales de esa comisión era estimular «la descentrifugación de los habitantes de las ciudades que ya se ha ido operado por el establecimiento de los tranvías eléctricos que deben considerarse como elemento de progreso e Higiene» ${ }^{50}$

Pero, el higienismo argentino desde hacía tiempo había centrado sus preocupaciones en los conventillos (o habitaciones colectivas) que eran considerados focos de pestilencia. Al igual que en Brasil la epidemia de fiebre amarilla ocurrida en Buenos Aires en 1871 había transformado radicalmente la percepción de los barrios populares. Para los higienistas argentinos Guillermo Rawson y Eduardo Wilde, los conventillos parecían concentrar todos los temores de la época. Rawson escribió, en 1885, el primer estudio sobre las casa de inquilinato en Argentina donde insistía en la necesidad de pensar a estos espacios como un verdadero peligro sanitario para los ricos. «De aquellas fétidas pocilgas cuyo aire jamás se renueva y en cuyo ambiente se cultivan los gérmenes de las más terribles enfermedades, salen esas emanaciones, se incorporan a la atmósfera circunvecina y son conducidas por ella, tal vez, hasta los lujosos palacios de $\operatorname{los}$ ricos» $\rangle^{51}$.

Para los primeros higienistas ese miedo al contagio se confundía con la propagación de los miasmas y del aire mefítico. Para Wilde (1883), por ejemplo, era «evidente que cuanto menos aseada era una ciudad, cuanto más depósitos de materias putrescibles contenga, tanto menos higiénico será el suelo, y por lo tanto, menos puro el aire que se encontrará cargado de gases y de vapores dañinos. ¿Cómo resolver? No exponiendo al aire materias orgánicas o minerales que, bajo la acción del calor y de la humedad puedan dar lugar al desprendimiento de gases extraños a la atmósfera» ${ }^{52}$. Este catedrático titular de Higiene y Medicina Legal de la Facultad de Ciencias médicas de la entonces llamada Universidad de la Capital, articuló su «Curso de Higiene Pública» de 1883, a partir de teorías infeccionistas vinculadas con las antiguas tesis de la generación espontánea. Wilde, como un exponente tardío del infeccionismo estudiado por Ackerknecht, aún se refería al peligro representado por los miasmas y

\footnotetext{
49 ARMUS, (1995) p. 82.

50 Ibidem.

51 Apud. PAes (1970), El Conventillo, Buenos Aires, Centro Editor de América Latina, p. 16.

52 Wilde, Eduardo (1883), Curso de Higiene Pública, Buenos Aires, Imprenta y librería Mayo, p. 50.
} 
criticaba duramente la aplicación de cuarentenas. Su preocupación estaba centrada en la ciudad y en los focos de pestilencia representados por mataderos y conventillos.

Los «cortiços» en Brasil, y los «conventillos» en Argentina, se transformaron en el objeto privilegiado de intervenciones sanitarias que, muchas veces, solo podían legitimarse por recurso a la fuerza policial. Como afirma S. Chalhoub, «Las clases pobres no pasaron a ser vistas como clases peligrosas apenas porque pudieran ofrecer problemas para la organización del trabajo. Los pobres ofrecían también el peligro del contagio. El propio peligro social representado por los pobres aparecía al imaginario político brasileño de fines de siglo XIX a través de la metáfora de la enfermedad contagiosa (...)Entonces se diagnosticó que el tipo de habitación de los pobres era nocivo a la sociedad porque las viviendas colectivas serían focos de irradiación de epidemias, a demás de, naturalmente, terrenos fértiles para la propagación de vicios de todo tipo» ${ }^{53}$.

Como vemos esta preocupación por los barrios populares parece que era, al menos en Brasil y Argentina, independiente del modo como se pensaba la etiología de las enfermedades. Desde Wilde (1883) hasta Coni (1907), las preocupaciones con el conventillo y las estrategias de higienización pudieron reiterarse sea por referencia a los miasmas o a los microbios. En diversas ocasiones estos discursos pudieron superponerse y confundirse, como puede observarse en esta referencia extraída de los Anales del III Congreso Médico Latino Americano de 1907: «al mefitismo, a las ratas y a la viciación de las aguas de nuestras habitaciones urbanas, hay que agregar las humedades, las filtraciones nauseabundas. (..)Ahora que está plenamente demostrado que los microbios tienen su origen en las tierras y aguas insalubres, en el suelo infectado de las ciudades podemos calcular el número de vidas que pueden ahorrar las medidas de higiene pública» ${ }^{54}$.

Paralelamente a la convivencia entre miasmas y microbios, en el higienismo de inicios de siglo, parecen haber podido convivir medidas más o menos eficaces como la distribución de vacunas, el control del agua y cloacas, las obras de saneamiento básico, la desaparición de pantanos, con medidas coercitivas, menos eficaces pero no menos utilizadas. «En ese marco, las inspecciones violentas, los «desalojos», la destrucción de muebles y viviendas, convivían con la obligación de presentar certificado de vacuna, y con la aparición de los primeros carteles educativos de publicidad» ${ }^{55}$. La metáfora de la guerra y la idea de amenaza, tan querida por los higienistas, dotaba de legitimidad a esas intervenciones coercitivas, consideradas de emergencia e inevitables, aun cuando se repitieran por décadas.

La guerra suponía enemigos que debían ser combatidos, y esos enemigos formaban parte del medio, del ambiente que se respiraba en las habitaciones y barrios populares, considerado como un universo saturado de gérmenes patógenos. «Aunque se

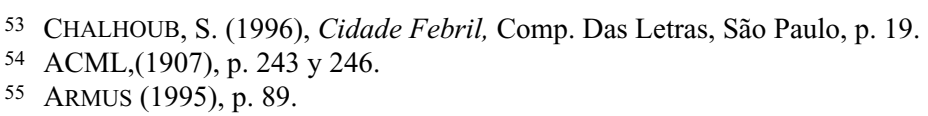


tratara de factores del medio ambiente, esa paranoia del contagio tendía a asimilar los peligros de los microbios con el hábitat donde ellos eran frecuentemente encontrados, y luego con los habitantes de esos locales. Por ese camino, la vivienda precaria, el pobre y la pobreza en general quedaron registrados no solo en términos médicos sino también en términos morales y políticos ${ }^{56}$. Como afirmaba Wilde: «La higiene pública es la higiene de los pobres. El pobre reclama el amparo de un poder que se ocupe de él, que haga las veces de protector para con él, que haga lo que hace un padre con su propia familia, con sus hijos destituidos de vigor y de medios» ${ }^{57}$. Vemos reiterarse aquí un argumento ampliamente defendido por los higienistas. Si la pobreza y la enfermedad debían ser pensadas como inseparables, entonces, como afirma Esteban Rodríguez Ocaña ${ }^{58}$, la clase obrera se constituía como una clase peligrosa en tres sentidos: por el riesgo de disminución de la productividad asociado a las enfermedades y a las debilidades morales; por la amenaza permanente a la salud de la colectividad (contagio e insurrección); por la amenaza a la fuerza del Estado al comprometer las generaciones futuras por los efectos del alcohol y las enfermedades.

Lo cierto es que, la cuestión de la vivienda popular higienizada se encuentra a mitad de camino entre las estrategias sanitarias necesarias y deseables como la canalización de agua y desagües, el desplazamiento de basurales o el control de ratas, y estrategias compulsivas o de control social que pueden ser resumidas en este documento de 1906: «A população que se deslocaba não tinha onde morar, alojava-se aquí, com armas e bagagems, para amanhá se remover a um outro ponto. Foi se afastando do centro quando os meios o permitiam; foi se aglomerando no centro, tornando mais perigosa a sua estadia, quando os recursos ordinários eram parcos $\rangle^{59}$. No es posible desconocer que las estrategias sanitarias relativas a la habitación colectiva y a aquellos considerados como focos de insalubridad resultaron, al menos en Brasil y Argentina, compulsivas y en muchos casos hasta brutales. Pero, si queremos huir de la llamada «hermenéutica de la sospecha» ${ }^{60}$, si pretendemos avanzar en la comprensión de las condiciones discursivas que posibilitaron esas y otras estrategias, será necesario que no limitemos nuestro análisis exclusivamente a las prácticas de control social.

No es posible desconocer la existencia de un conjunto de medidas sanitarias operativas, adoptadas por los higienistas pre y post pasteurianos, paralelas al control de las conductas y de los hábitos del mundo de la pobreza. Pero, el conflicto existente entre esos dos espacios parece ser uno de los problemas constitutivos de la salud pública que, aún hoy, muchos países no consiguen resolver. «La inspección de viviendas populares privadas versus la salud pública planteaba la cuestión de los dere-

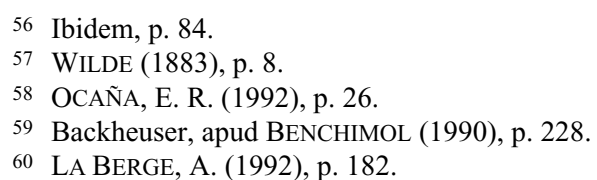


chos individuales y de la propiedad privada versus el derecho del estado de intervenir en nombre de la salud colectiva. Este problema de conflictos de intereses entre privacidad y salud pública continúa sin resolverse durante todo el siglo XIX»» ${ }^{61}$ Este conflicto reaparece en Brasil en 1904 con la llamada «Revolta da Vacina», y persiste durante las primeras décadas del siglo XX, tanto en Brasil cuanto en Argentina con las resistencias operadas contra los desalojos y las demoliciones.

Quizás, el análisis de esas estrategias nos permita comprender el modo como los higienistas de fin del siglo XIX e inicios del siglo XX se posicionaron frente al problema de la pobreza. Muchas veces se intentó resumir esta compleja relación en una frase de Virchow: «los médicos son los protectores naturales de los pobres». Esta frase ambigua resume las contradicciones entre una preocupación por las desigualdades sociales, y una extraña exaltación de actitudes paternalistas que, como sabemos, conducen casi inevitablemente a multiplicar los controles y reducir las libertades. Y es el propio Virchow quien confirma este riesgo cuando afirma: «como en la vida de las naciones, también en la vida de los individuos el estado de salud del todo está determinado por el bienestar y por la estrecha interrelación de las partes; la enfermedad aparece cuando los miembros individuales comienzan a caer en un estado de inactividad peligrosa para la nación o a llevar existencias parasitarias a expensas del todo ${ }^{62}$. Entonces los médicos higienistas se erigieron en guías de la sociedad; creyeron conocer, mejor que los propios individuos, que es lo que sería mejor para ellos, y entonces, creyeron poder decirles como debían actuar, comportarse, pensar.

\section{MIASMAS, MICROBIOS Y CONVENTILLOS}

Desde Ackerknecht a nuestros días se afirma que a partir de la emergencia de la microbiología, que concede el triunfo definitivo al contagionismo, fue edificada una «nueva higiene» que finalmente privilegiaba medidas eficaces ${ }^{63}$ y científicamente fundamentadas. La microbiología dotaría a esta nueva higiene de una base científica para explicar y legitimar muchos de los procedimientos que la higiene clásica había puesto en práctica para combatir ese omnipresente enemigo al que llamaba «mias-

61 Ibidem, p. 323. Como lo advierten Georges Duby y Michel Perrot en la Historia de la Vida Privada no es posible hablar, en sentido estricto de vida privada de los trabajadores pobres hasta inicios del siglo XX. Hasta entonces los espacios de descanso y trabajo conviven, y el mundo de la calle (el mundo exterior) y el de la casa no tienen fronteras bien definidas. Deberíamos hablar, en realidad, de un conflicto entre la existencia individual y las exigencias colectivas.

62 Hacking, I. (1995), La Domesticación del Azar, Gedisa, Barcelona, p. 272.

63 Hablar de medidas eficaces no significa hablar de medidas populares o fácilmente aceptadas, las resistencias a la vacunación nos dan un testimonio de su impopularidad. 
ma»; permitiéndole finalmente desplazar los argumentos infeccionistas en favor de los contagionistas.

Para Canguilhem ${ }^{64}$, la medicina moderna alcanza estatuto de cientificidad en el momento de emergencia de la microbiología y de la bacteriología. Hasta entonces, el discurso higienista bordea ese espacio ambiguo entre lo moral y lo técnico que no podría ser caracterizado como «científico» aún cuando hayan existido (antes y después de Pasteur y Koch) estrategias sanitarias efectivas y operativas. «Antes de Pasteur, la higiene era inexistente, ella solo deviene una verdadera ciencia a partir de los trabajos pasteurianos sobre la generación espontánea» ${ }^{65}$. Entonces, resulta necesario definir el estatuto epistemológico de esa higiene clásica que posibilitó la creación de medidas sanitarias efectivas generales e interrogarse por cuales fueron los mecanismos que posibilitaron su transformación hasta dar lugar a estrategias concretas de combate y prevención a diversas enfermedades específicas.

Independientemente de la disputa relativa al peso de las medidas sanitarias en el descenso de la mortalidad ${ }^{66}$, parece innegable que los resultados favorables conseguidos por los nuevos higienistas, se debieron a la reiteración de medidas propias del higienismo clásico.Como afirman Murard y Zylberman, aún careciendo de bases «serias», los higienistas podían enorgullecerse de haber conseguido buenos resultados por una simple razón: las medidas por ellos propuestas tendían, sin saberlo, a actuar sobre las cadenas de transmisión. «Por infundada que parezca esta teoría, ese programa prueba abundantemente su pertinencia frente a las enfermedades que circulan por la vía fecal-oral, como cólera, disentería y fiebre tifoidea, cuya disminución precipitan notablemente» ${ }^{67}$.

Pero, si aceptamos que el higienismo carece de toda base epistemológica sólida será inevitable creer que existe una anterioridad del poder sobre el saber, o de la acción sobre la episteme. Según esta línea de pensamiento podríamos concluir que la emergencia de la microbiología habría dotado de contenido epistémico a esa serie de acciones inconexas que, a partir de allí, se transformaron y se adaptaron a las exigencias de ese nuevo saber.

Creemos que es necesario responder a la tesis que afirma que el higienismo clásico era ajeno al ámbito del saber científico: algo así como una aproximación intuitiva, extraña heredera, por anticipación, de los principios pasteurianos. Por otra parte, será necesario volver, una vez más, sobre la distinción (teórica y política) supuesta por Ackerknecht, con la finalidad de intentar mostrar que esa distinción, aunque pueda resultar válida en ciertos contextos, no puede ser universalizada.

64 CANGuilhem, G. (1993), Ideologie et rationalité dans l'histoire des sciences de la vie, París, Vrin.

65 Apud. Murard y ZYLBERMAN (1996), p. 98.

66 A propósito de esa disputa ver MURARD y ZYLBERMAN, op.cit., p. 91.

67 Ibidem, p. 91. 
Las conquistas introducidas por Lavoisier en sus estudios sobre la respiración, a los cuales nos referimos al tratar el «aerismo», así como las experiencias de Spallanzani sobre la digestión, suscitan un interés creciente por las aplicaciones de la química a la medicina y dotan a la higiene de un suelo discursivo capaz de crear estrategias operativas para combatir las enfermedades de transmisión hídrica, como el cólera, o de transmisión aérea, como la tuberculosis. Pero el higienismo no se reducía a intervenciones puntuales relativas al aire y al agua, junto a ellas se multiplicaron apreciaciones morales, muchas veces cargadas de prejuicios. El higienismo parece proceder por multiplicación de analogías y de desplazamientos por los cuales generaliza los conocimientos obtenidos en un ámbito, en este caso la química y la fisiología, al conjunto de las actividades humanas.

Como vimos esos desplazamientos encuentran su fundamento en la clásica asociación, retomada por Cabanis, entre características físicas y actitudes morales. Esta asociación forma parte del suelo discursivo de la episteme clásica, «conocer la fisiología, era al mismo tiempo conocer la sociología y la psicología. Las ciencias sociales eran hasta Comte, de tal modo balbuceantes, que se aceptaba sin discutir, esa afirmación, implícitamente formulada por Saint Simon, que la humanidad obedece a las mismas reglas que el hombre físico» ${ }^{68}$.

Entonces, es posible decir que el higienismo toma prestado un conocimiento bien fundado: es inicialmente heredero de la revolución científica operada en la química por Lavoisier, así como es heredero de la fisiología y la estadística. Sin embargo, no es reductible a ninguno de estos conocimientos, parte de allí y generaliza las nociones propias de estos dominios a espacios que le son ajenos, como el comportamiento o la moral. A partir de allí construye discursos y estrategias que, muchas veces, resultaron operativas y eficaces, aun cuando encontraran su fundamento teórico en preceptos morales, que hoy puedan parecernos próximos a la superstición o al mito. Esta continuidad entre lo físico y lo social o moral formaba parte de la episteme de los higienistas de la primera mitad del siglo XIX, donde se confundían argumentos provenientes de las ciencias físico-químicas, de la fisiología y de lo que hoy llamaríamos de ciencias sociales. En el caso de los higienistas la teoría de la respiración, la química, y la estadística, funcionaban como legitimadores y «justificadores» de medidas que eran ajenas al ámbito del que partieron. Pensemos como ejemplo, en la preocupación por cubrir los pantanos con el fin de evitar la producción de sujetos perezosos y moralmente condenables.

Este deseo de acceder a la totalidad parece ser inseparable del higienismo. Como afirma Bruno Latour: «La enfermedad, tal como es definida por los higienistas, puede ser causada por casi cualquier cosa. Nada debe ser ignorado, nada debe ser desconsiderado. Muchas causas pueden ser encontradas, lado a lado, que impiden con-

68 ACKERKNECHT (1986), p. 198. 
ceder a una de ellas la posición de causa definitiva (...).Todo debe ser considerado» ${ }^{69}$. Este todo significaba suelo, aire, agua, conductas, deseos, etc. Pero, si nada de lo humano era ajeno al higienismo, nada lo habilitaba para intervenciones efectivas y puntuales que negarían esa totalidad.

Así como la higiene clásica no puede ser reducida a los estudios sobre la respiración aún cuando encuentre allí el fundamento para muchas de sus intervenciones; la nueva higiene, no puede ser reducida a la microbiología. Sin embargo, la nueva higiene operó, también, por desplazamiento y contagio de cientificidad, cada vez que pretendió encontrar para sus intervenciones y para sus estrategias de prevención una explicación que resultaba de una generalización abusiva de la microbiología a espacios que le eran ajenos. La higiene posterior a Pasteur reproducía así el mismo esquema que la higiene clásica: al generalizar sus afirmaciones a partir de un conocimiento bien fundado podía llegar a enunciar que (a)toda enfermedad se debe a un microbio, (b) todo microbio precisa para multiplicarse de condiciones higiénicas precarias.

El higienismo no restringe su interés a las enfermedades contagiosas. Los primeros higienistas se preocuparon no solo con el contagio sino con otras cuestiones sanitarias tales como las condiciones de vida precarias, la prostitución, la ebriedad, la higiene de los alimentos, la escuela, etc. Estas preocupaciones no desaparecieron con la emergencia de la microbiología aunque fue cada vez mayor el espacio ocupado por las estrategias de prevención de las enfermedades contagiosas, específicamente: vacunación y desinfección. Cuando los higienistas post-pasteurianos hablan de hacinamiento o de degeneración moral y física, se mezclan y confunden los nuevos argumentos microbiológicos, los antiguos argumentos químicos aeristas y los argumentos morales y sociales.

Fantini afirma que «El éxito de la microbiología llevó a buscar para todas las enfermedades una causa microbiana, aun para aquellas que, como hoy sabemos, son debidas a carencias o a defectos genéticos. En numerosos casos este reduccionismo se reveló inadecuado» ${ }^{70}$. Si por una parte la microbiología instaura explicaciones reduccionistas claramente «contagionistas», por otra, estos argumentos pueden convivir, muchas veces sin dificultad, con los antiguos argumentos infeccionistas. Antes de Pasteur la higiene podía hacer derivar conductas y comportamientos morales de argumentos aeristas: «por ejemplo que los habitantes de las montañas, a fuerza de vivir en un medio salubre, terminan por adquirir salud moral y vigor físico, una y otra inseparables en la época en que se insiste en señalar la relación entre lo físico y lo moral» ${ }^{71}$.

Después de Pasteur, muchas veces sus contemporáneos han simplificado y desnaturalizado sus investigaciones, dotándolas de una generalidad que no poseían pero

69 LATOUR, B. (1988), p. 20

70 FANTINI, B. (1999), «La microbiologie medicale», en GRMEK, M. (1999), Histoire de la pensée médicale en occident, Seuil, París, p. 134.

71 Dagognet, F. (1998), Savoir et Pouvoir en Médecine, Institut Synthélabo, Le Plessis, p. 129. 
que era compatible con las premisas higienistas clásicas: «ellos han creído en la pureza absoluta de las simas de las montañas que los microbios no alcanzarían. En lugar de comprender a Pasteur como un sabio que minuciosamente construye sus experiencias y se preocupa, hasta el infinito, por las condiciones en que ellas ocurren, han amplificado las resonancias afectivas de sus descubrimientos, y rápidamente se han deslizado de la legítima preocupación científica por la completa esterilización y por la estrecha vigilancia de los mínimos gestos o instrumentos puestos en acto en el laboratorio, hacia el temor generalizado a las «suciedades» invisibles e desconocidas. Se ha transpuesto al universo cotidiano lo que solo valía para el artificio de una verificación. Se ha creado una neurosis colectiva de la contaminación $\gg^{72}$.

Con relación a la vivienda popular esa fobia al contacto y a los aires patógenos se reitera en el higienismo anterior y posterior a Pasteur. Aquello que Hallé llamaba circunfusa, la preocupación por las habitaciones, la meteorología, el clima, la hidrología; continuó siendo uno de los temas articuladores del nuevo higienismo. Observando la cronología comparada de la ley del 15 de septiembre de 1902 sobre la protección de la salud pública en Francia, con los descubrimientos pasteurianos ${ }^{73}$, resulta que, con relación a la salubridad de los inmuebles esta ley aparece como la continuación y el refuerzo de la ley de 1850 sobre alojamientos insalubres. La ley del 15 de septiembre estableció la obligatoriedad de cumplir normas higiénicas de construcción para los nuevos inmuebles, a fin de garantizar buena aireación, iluminación y ventilación; con relación a las habitaciones reconocidas como insalubres se reforzaron y ampliaron los poderes públicos para poder enfrentar las resistencias suscitadas por la ley de 1850 . Por una parte se establecieron sanciones contra aquellos que no cumplían con las exigencias de saneamiento; por otra parte aparecieron medidas de auxilio a los propietarios que tendían a proteger el derecho de propiedad. Se crearon medidas tendientes a posibilitar el saneamiento de aquellas viviendas que podían ser reformadas, como la liberación del pago de impuestos a puertas y ventanas, al tiempo que se estipulaba la obligación de indemnizar justamente a los propietarios de habitaciones que, por ser consideradas insalubres, deban ser demolidas.

Así, las medidas dirigidas contra las viviendas populares colectivas o individuales se mantuvieron más o menos intactas antes y después de Pasteur. Si con relación a la vacunación los cambios fueron radicales, con relación a las viviendas insalubres la continuidad era completa. En 1902 podía resultar sorprendente que «en el país de Pasteur los impuestos a las puertas y las ventanas que privan de sol y de aire a los habitantes de los alojamientos pueda aún estar en vigor» ${ }^{74}$. Una afirmación exacta-

\footnotetext{
72 DAGOGNET, (1998), p. 158.

73 Esta cronología es expuesta en el texto de Claire SALOMON-BAYET (1986), «Pasteur y la Revolución Pasteuriana», en el Anexo E, y es analizada en el texto de Robert Carvais.

74 CARVAIS, R (1986), «La Maladie, la loi et les Moeurs». In Salomon-Bayet, C. (org) (1986), Pasteur et la Revolution Pastorienne, Payot, París, p. 288. Para Carvais esta ley de 1902, específicamente los
} 
mente idéntica podría haber sido enunciada un siglo antes, entonces los higienistas podrían haberse sorprendido de que «en el país de Lavoisier los impuestos a las puertas y las ventanas que privan de sol y de aire a los habitantes de los alojamientos pueda aún estar en vigor». Es que como afirma Anne la Bergue «Los objetivos del movimiento de fines de siglo XIX eran similares a los objetivos de los reformadores de inicios del XIX. El efecto práctico inmediato que resultó de los esfuerzos del movimiento de salud pública de fines del XIX fue la ley de salud pública de 1902, que en comparación con la ley de salud pública de 1848, aparece como la culminación de los esfuerzos de los higienistas de inicios de siglo» ${ }^{75}$.

Cuando nos referimos a la vivienda popular la continuidad entre la nueva y la antigua higiene es evidente. Las medidas de saneamiento que antes encontraban explicaciones químicas, encontraron, a partir de Pasteur, explicaciones biológicas. Entonces, la cuestión del medio externo, el ámbito donde los microbios pueden desarrollarse y reproducirse, pasó a ocupar un lugar central. Y es en el propio Pasteur donde los higienistas creyeron encontrar el punto de partida para muchas de sus generalizaciones: «el polvo es un enemigo doméstico que todos conocen. ¿Quién de nosotros no ha visto un rayo de sol penetrando por una persiana en un cuarto mal iluminado?. El aire de ese cuarto está todo repleto de pequeñas partículas de polvo, de mil pequeñas «nadas», que no pueden ser pasadas por alto, porque es posible que lleven junto con ellas la enfermedad o la muerte: el tifus, el cólera, la fiebre amarilla, y tantas otras enfermedades. El aire de ese cuarto está repleto de ellos. Nosotros no los vemos, porque ellos son tan pequeños, de un volumen tan débil (...) $\rangle^{76}$. Hasta que punto pudo generalizarse una afirmación de este tipo, desplazando aquello que se refería a un espacio concreto para todo el ámbito de la existencia cotidiana, puede testimoniarlo esta conferencia pronunciada en Montevideo en el III Congreso Médico Latino Americano.

Allí todas las explicaciones parecen estar articuladas en torno a una «neurosis de la contaminación», a un temor generalizado a los seres invisible y desconocidos. En ese Congreso (Montevideo, 1907) Millot Grané dirá que la falta de reglamentación sanitaria acarrea inevitables problemas, entre los cuales: «el primero y el más grave es la invasión de todos los conductos subterráneos de los inmuebles por gases mefíticos. Sigue a esto como consecuencia lógica la producción de mefitismo en el subsuelo de las habitaciones y la aparición de ratas. Desde ese momento el mefitismo invade la casa dotando al ambiente irrespirable de gases deletéreos e infecciosos que provienen de la cloaca pública y de los caños domiciliarios donde la falta de ventilación produce la putrefacción de sustancias residuales. Para darnos cuenta de la influen-

artículos 12 y sig. Referidos a la vivienda, aparece como «la ley marco que sirve para difundir los principios pasteurianos en materia de higiene». Creemos en cambio que la misma evidencia en muchos aspectos una clara continuidad con el higienismo clásico.

75 LA BERGUE (1992), p. 326.

76 Apud Dagognet (1998), p. 158. 
cia de esa insalubridad basta recordar que en el análisis de aguas residuales de París se han contado dieciocho millones de microorganismos por centímetro cúbico» ${ }^{77}$. Esta exposición estaba centrada en el problema de los «conventillos» que eran caracterizados como conjunto de cuartuchos fétidos y oscuros, sinónimo de falta de aire, falta de sol y falta de aseo, donde se alojaban colectivamente las clases pobres y donde la tuberculosis hacía su mayor número de víctimas. Combatir ese «flagelo» exigía (aunque no existan dudas de la existencia de bacilos específicos) «luz solar, aire y agua puros y abundantes» único medio para controlar el «mefitismo, y la putrefacción».

En 1907 se presentaba un cuadro sanitario con un idioma propio de inicios del siglo XIX, era el mefitismo, el aire viciado, el gas carbónico quienes deberían ser atacados, pero también las bacterias y los microbios. No se afirmaba que, por generación espontánea, el mefitismo produciría microbios. Se decía que, para que los microbios pudieran proliferar era necesario que existieran determinadas condiciones en el medio que se encontraban reunidas en un espacio físico: el conventillo considerado como sinónimo de «proliferación de gérmenes», pero era también, recuperando la antigua asociación entre lo físico y lo moral, como un espacio que evidenciaba «el agotamiento de la salud física y moral de sus habitantes» ${ }^{78}$

Según parece no es posible afirmar que la higiene «deviene una verdadera ciencia a partir de los trabajos pasteurianos sobre la generación espontánea y sobre las enfermedades del bicho de seda». Los ejemplos que aquí analizamos, nos permiten concluir, que ese proceso de cientificidad no ocurrió de modo espontáneo y necesario. Aunque existieran ineludibles diferencias entre uno y otro, persistían, en los márgenes, discursos donde esos horizontes teóricos podían resultar compatibles y complementarios. Es esto lo que parecía ocurrir con la vivienda popular higienizada y con las epidemias a ella asociadas. Allí las mismas estrategias aparecían con argumentos que hoy pueden parecernos contradictorios

En el caso de la vivienda popular aparecen cuestiones muy diferentes a aquellas que deben ser analizadas cuando se trata de contener una epidemia como la de cólera o de fiebre amarilla. En el caso concreto que aquí nos ocupa no es posible identificar, las teorías miasmáticas con una «teoría social de las epidemias», ni afirmar con Ackerknecht ${ }^{79}$ que «el anti-contagionismo era, en cierta medida, un combate a favor de la libertad».

Al hablar de vivienda popular colectiva, de islas de insalubridad y de las enfermedades o epidemias a ellas vinculadas, los discursos miasmáticos y contagionistas parecen poder convivir sin extrema dificultad, reproduciendo, según sean las necesidades coyunturales, las mismas estrategias más o menos autoritarias. Las distinciones taxativas parecen borrarse en favor de la definición de estrategias operativas. Como

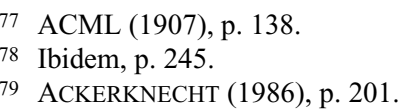


afirma Delaporte ${ }^{80}$ : «es necesario liberarse de la idea que sostiene que las medidas de segregación eran dictadas por los conservadores y que los opositores a esas medidas eran liberales (...). Estas correlaciones estrictas son históricamente inadecuadas». De igual modo, ya no parece legítimo hablar del enfrentamiento de un discurso precientífico y otro científico, sino más bien de controversias y continuidades internas al propio discurso higienista. El higienismo clásico parece partir de un conjunto de premisas, más o menos operativas, que aspiran a la universalidad y que lateralmente reproducen y generalizan aquello que ocurre en dominios científicos específicos: la química y la estadística. Por su parte, el nuevo higienismo parte de un conjunto de medidas, más o menos operativas, que amplían, reproducen y generalizan aquello que en otro dominio científico aparece como incontestable: la microbiología.

Es que, a partir del momento en que el terror a los microbios se generaliza, cuando se difunde eso que Dagognet llama una «neurosis colectiva de la contaminación», una «fobia a los contactos, a los aires patógenos y a los medios urbanos infectados», el discurso microbiológico puede simplificarse y generalizarse reproduciendo tanto los viejos temores y miedos como las antiguas estrategias (operativas o no) propias del higienismo clásico.

\section{BIBLIOGRAFÍA}

ACKerknecht, H. E. (1986), La médecine hospitaliére à Paris, París, Payot. University Press

(1982), A short History of Medicine, Baltimore \& London, The John Hopkins

Anales del III Congreso Médico Latino Americano, (1907), Montevideo, (ACML,1907).

Anales del IV Congreso Médico Latino Americano, (1913), Lima, (ACML, 1913).

Anales del Departamento Nacional de Higiene, (1895), Buenos Aires, (ADNH, 1895).

Armus, D. (org.) (1995), Huelgas, Habitat y Salud, Buenos Aires, Sudamericana.

(1990), Mundo Urbano y Cultura Popular, Buenos Aires, Sudamericana.

BALdwin, P. (1999), Contagium and the State in Europe. 1830-1930, Cambridge, Cambridge University Press.

Benchimol, J.L. (1990), Pereira Passos: Um Haussmann tropical, Río de Janeiro, Biblioteca Carioca.

Bourdelais, P. (1988), Peurs et Terreurs face à la Contagion, París, Fayard.

(1998), «Entre médicine et societé», en Comunications, $n^{\circ}$ 66, París, Seuil.

CANGuilhem, G. (1993), Ideologie et rationalité dans l'histoire des sciences de la vie, París, Vrin.

CARvais, R. (1986), «La Maladie, la loi et les Moeurs», en Salomon-Bayet, C. (org) (1986), Pasteur et la Revolution Pastorienne, París, Payot.

80 Delaporte, F. (1986), Disease and Civilization, MIT Press, Cambridge, p. 148. 
Coleman, William (1982), Death Is a Social Disease. Public Health and Political Economy in Early Industrial France, Madison, The University of Wisconsin Press.

Chalhoub, S. (1996), Cidade Febril, São Paulo, Comp, Das Letras.

Dagognet, F. (1998), Savoir et Pouvoir en Médecine, Le Plessis, Institut Synthélabo.

Duby, G. (1985), Histoire de la vie Privée, París, Seuil.

Delaporte, F. (1986), Disease and Civilization, Cambridge, MIT Press. (1998), «Le Cholera: present et passé», en Comunications, nº66, París, Seuil. (1995), Les Epidemies, París, Explora.

FAUre, O. (1993), Les Français et leur médecine au XIX siecle, París, Belin.

FAnTini, B. (1999), «La microbiologie medicale», en Grmek, M. (1999) Histoire de la pensée médicale en occident, París, Seuil.

Foucault, M. (1997), Naissance de la clinique, París, PUF.

GRMEK, M. (1997), Histoire de la pensée médicale en occident, París, Seuil. (1999), Histoire de la pensée médicale en occident, París, Seuil.

HACKING, I. (1995), La Domesticación del Azar, Barcelona, Gedisa.

JORLAND, G. (1999/2000), Séminaire «Les Lumieres Scientifiques: Le mouvement hygiéniste en France au XIXéme siécle», París, École des hautes études en sciences sociales.

Jordan, D. (1995), Transforming Paris: the life and labors of Baron Haussmann, New York, The Free Press.

La Berge, A. (1992), Mission and Method, Cambridge, Cambridge University Press.

LAtour, B. (1988), The Pasteurization of France, Cambridge, Harvard University Press. (1986), «El teatro de la prueba», In SALOMON-BAYET, C. (org) (1986), Pasteur et la Revolution Pastorienne, París, Payot.

LAvoisier, E. (1777), Memorias. L'air et L'eau, París, Librairie Armand Colin, ed. de 1923.

LÉCUYER, B. (1986), «L'Hygiène en France avant Pasteur», en Salomon-Bayet, C. (org) (1986). Pasteur et la Revolution Pastorienne, París, Payot.

LÉONARD, J. (1992), Médicins, Malades et Societé, París, Sciences en Situation.

MAZzolini, R. (1997), «Les lumières de la raison: des systèmes médicaux à l'organologie naturaliste», en Grmek, M. (1997), Histoire de la pensée médicale en occident, París, Seuil.

MurARD, L. y ZylBerman, P. (1996), L'Hygiène dans la République, París, Fayard.

OCAÑA, Esteban R. (1992), Por la salud de las naciones. Higiene, Microbiología y Medicina social, Madrid, AKAL.

PÁEZ, Jorge (1970), El Conventillo, Buenos Aires, Centro editor de América Latina.

REY, R. (1993), «Hygiène et Souci de soi», en Comunications. n 56, París, Seuil.

Salomon-Bayet, C. (org) (1986), Pasteur et la Revolution Pastorienne, París, Payot.

StePAn, Nancy (1996), The hour of eugenics, London, Cornell University Press.

Vigarello, G (1999), Histoire des practiques de santé, París, Seuil.

(1985), Le prope et le sale, París, Seuil.

(1993), «Modeles anciens et modernes d'entretien de la santé», en Comunications, ${ }^{\circ} 56$, París, Seuil.

VILlERMÉ, L. (1840), Tableau de l'état physique et moral des ouvriers, París.

WiLdE, E. (1883), Curso de Higiene pública, Buenos Aires, imprenta y librería Mayo. 